\title{
Extensão Tecnológica Inovadora para o combate ao COVID-19 através da Iniciativa Startup Experience da UFPR
}

\author{
Innovative Technological Extension to combat \\ COVID-19 through UFPR's Startup Experience \\ Initiative
}

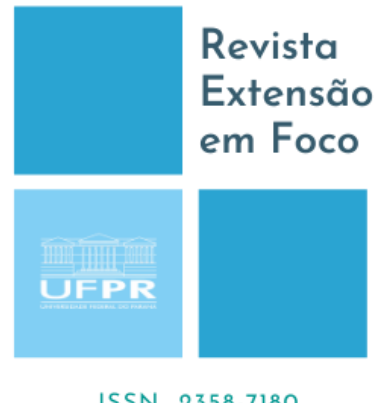

ISSN $2358-7180$

\begin{abstract}
Allana Resende Santos ${ }^{1}$, Isabella Stallbaum Schemiko², Pauline Almeida Rosa ${ }^{3}$, Bernardo Davoglio ${ }^{4}$, Ricardo Ferreira Freitas ${ }^{5}$, Michelle Aparecida Coelho Moreira ${ }^{6}$, Ihana Aguiar Severo 7 , Selma Aparecida Cubas ${ }^{8}$, José Viriato Coelho Vargas ${ }^{9}$, André Bellin Mariano ${ }^{10}$

${ }^{1}$ Graduanda em Farmácia. Universidade Federal do Paraná (UFPR), Curitiba, Paraná, Brasil. E-mail: allanaresendesantos@gmail.com

${ }^{2}$ Graduanda em Farmácia. Universidade Federal do Paraná (UFPR), Curitiba, Paraná, Brasil. E-mail: bellaschemiko@gmail.com

${ }^{3}$ Graduanda em Farmácia. Universidade Federal do Paraná (UFPR), Curitiba, Paraná, Brasil. E-mail: paulinealrs17@gmail.com

${ }^{4}$ Graduando em Engenharia Química. Universidade Federal do Paraná (UFPR), Curitiba, Paraná, Brasil. E-mail: berdavoglio@gmail.com

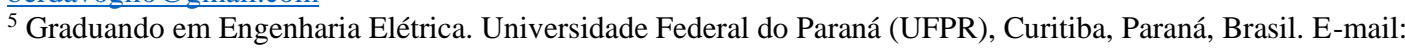
riccardoffreitas@gmail.com

${ }^{6}$ Doutora. Universidade Federal do Paraná (UFPR), Curitiba, Paraná, Brasil. E-mail: michellemoreira0917@gmail.com.

${ }^{7}$ Doutora. Universidade Federal do Paraná (UFPR), Curitiba, Paraná, Brasil. E-mail: ihana.aguiar@gmail.com. Orcid: https://orcid.org/0000-0001-5429-6052

${ }^{8}$ Doutora. Universidade Federal do Paraná (UFPR), Curitiba, Paraná, Brasil. E-mail: selmacubas@ gmail.com. Orcid: https://orcid.org/0000-0002-5698-995X

${ }^{9}$ Doutor. Doutor. Universidade Federal do Paraná (UFPR), Curitiba, Paraná, Brasil. E-mail: vargasjvcv2@gmail.com. Orcid: http://orcid.org/0000-0002-1458-2908

${ }^{10}$ Doutor. Universidade Federal do Paraná (UFPR), Curitiba, Paraná, Brasil. E-mail: andrebmariano@ gmail.com. Orcid: https://orcid.org/0000-0002-1693-8947
\end{abstract}

\section{RESUMO}

A metodologia interdisciplinar Iniciativa Startup Experience, desenvolvida no Projeto de Extensão Ciência para Todos, consiste na aplicação dos conceitos de ensino de aprendizado baseado em problemas e/ou projetos e focados para o desenvolvimento da inovação e empreendedorismo com alunos do ensino médio, graduação e pós-graduação relacionando-se com o setor produtivo e ecossistema de inovação local (município e estado). Desta forma, a equipe do projeto focou seus esforços na criação de soluções práticas para combate da pandemia COVID-19 através do uso de ferramentas digitais para o controle e monitoramento do acesso aos espaços de estudo ou trabalho. $\mathrm{O}$ produto final foi disponibilizado para a sociedade através de vídeo tutorial que permite o uso da solução através de ferramentas digitais gratuitas. Além disso, foram desenvolvidas: i) solução semiautomatizada a partir de VBA (Visual Basic for Applications) e ii) aplicativo para celulares. Alunos dos cursos de Farmácia, Engenharia Elétrica e Engenharia Química integraram uma nova startup denominada "CHECK Acesso Fácil”. Esse sistema está em teste no Hospital Veterinário da UFPR para fazer a gestão de todos os médicos veterinários residentes e demais funcionários. Desta forma, através deste trabalho interdisciplinar a partir da Metodologia Startup Experience, foi possível realizar a capacitação de alunos universitários com as competências de gestão de projeto, soft skills, inovação, empreendedorismo, interdisciplinaridade e extensão tecnológica inovadora com a criação de uma solução que permite, através do monitoramento de acessos, o controle da saúde de equipes de trabalho em empresas e, até mesmo, alunos e professores em universidades e escolas.

Palavras-chave: controle de acessos, aplicativo, startup, interdisciplinaridade, COVID-19. 
The interdisciplinary methodology Startup Experience Initiative, developed in the project Science for All, consists of the application of project/problem based learning concepts, which are focused on the development of innovation and entrepreneurship for high school, undergraduate, and postgraduate students. This action has a relationship with the productive sector and local innovation ecosystem (city and state). In this way, the project team focused its efforts on creating practical solutions to combat the pandemic COVID-19 through the use of digital tools for controlling and monitoring access to study or workplaces. The final product was made available to society through a tutorial video that allows the use of the solution with free digital tools. Furthermore, the following were developed: i) semiautomated solution based on VBA (Visual Basic for Applications) and ii) cell phone application. Students from Pharmacy, Electrical Engineering and Chemical Engineering courses integrated a new startup called "CHECK: Easy Access". This system is being tested at the Veterinary Hospital of UFPR to manage all resident veterinarians and other employees. Thus, through this interdisciplinary work from the Startup Experience Methodology, it was possible to perform the training of university students with the ability of project management, soft skills, innovation, entrepreneurship, interdisciplinarity, and innovative technological extension. This initiative provided the creation of a solution that allows, through access monitoring, the health control of work teams in companies and even students and teachers in universities and schools.

Keywords: access control, application, startup, interdisciplinarity, COVID-19.

\section{INTRODUÇÃO}

A pandemia do novo Coronavírus, responsável pelo COVID-19, ou síndrome respiratória aguda grave do Coronavírus (SARS-CoV-2), resultou em uma mudança sem precedentes nos padrões socioeconômicos em todo o mundo. Este vírus emergente tornou-se um grande desastre de saúde pública já que em um curto período e com a fácil transmissão, o número de casos aumentou consideravelmente em diversos países. De acordo com a Organização Mundial da Saúde (OMS), não há um medicamento específico e $100 \%$ eficaz disponível até o momento, apesar da existência de algumas diretrizes com as melhores práticas que as nações podem adotar (HOSSAIN, 2021).

Diversas mudanças foram necessárias para controlar a disseminação do COVID19 e proporcionar maior segurança às pessoas, incluindo o distanciamento social, o uso de máscara médica pelo público em áreas afetadas pelo vírus e a higienização das mãos com soluções à base de álcool ou a lavagem das mesmas. Essas são algumas das medidas que se tornaram imprescindíveis para evitar a sua transmissão e contágio (BHATTACHARYA et al., 2021).

Diante desse contexto, o COVID-19 impactou sobre os setores sociais, incluindo os sistemas de saúde, governos, empresas, indústrias e instituições de ensino. As universidades, por exemplo, foram drasticamente afetadas pela pandemia, desencadeando medidas de isolamento social que afetou a educação em pelo menos 200 países (UNESCO, 2020). Este foi também o caso do Brasil, onde as universidades foram fechadas e, consequentemente, as aulas presenciais suspensas por tempo 
indeterminado. Contudo, é importante ressaltar que o ambiente universitário, enquanto centro de pesquisa, ensino e extensão, realiza e exprime de modo determinado a sociedade. Essas ações, por sua vez, consideradas como atividades essenciais, impactam diretamente nos diversos setores da economia, os quais corroboram com o progresso da ciência (SILVA, 2020).

Associado a estes aspectos, como muitos projetos de pesquisa continuam em desenvolvimento em laboratórios dentro das universidades, além das restrições ao uso de espaços físicos comuns, é crucial adotar medidas emergenciais de segurança em cada local a fim de garantir a saúde e bem-estar de docentes, discentes, técnicos administrativos e todos os demais envolvidos (SANTANA et al., 2020). Essas estratégias devem ser tratadas com máxima prioridade e rigor.

Portanto, o seguinte questionamento fez-se necessário: como manter o funcionamento das atividades universitárias de forma segura? Para atender a essa demanda, diversos estudos têm sido conduzidos na tentativa de contribuir para elaboração de abordagens de controle da disseminação do COVID-19 (MOUTER et al., 2021). Uma das opções é o rastreamento e gestão dos acessos a estes espaços para minimizar todo e qualquer caso de contágio pelo vírus (KUMMITHA, 2020).

Estratégias manuais de controle, baseadas em sistemas físicos, como o tradicional livro-ponto de registro, são, no entanto, trabalhosas e demoradas. Tais práticas podem ser rapidamente subjugadas pela magnitude da pandemia. Por outro lado, estratégias de rastreamento digital são atualmente mais aceitas. Esses sistemas têm sido considerados por departamentos e empresas no controle de informações de indivíduos sobre exposição potencial ao COVID-19. Além disso, os aplicativos digitais são ferramentas úteis de notificação instantânea, automática, eficiente e anônima sobre o risco, auxiliando na solicitação do indivíduo a entrar em quarentena (MOUTER et al., 2021).

Com o propósito de favorecer o controle de acesso ao ambiente universitário, surgiu uma ação voltada para o desenvolvimento de soluções relacionadas à pandemia, liderada por diversos pesquisadores da Universidade Federal do Paraná (UFPR), localizada na cidade de Curitiba (Paraná, Brasil). Tal ação está baseada no projeto do Edital "COVID-19 e agora?" da UFPR, que tem como objetivo primário a busca por estratégias de prevenção da contaminação do Coronavírus para o retorno seguro das atividades na instituição e, por sua vez, o planejamento e execução das mesmas. 
A partir disso, a Startup "Check - Acesso Fácil" foi criada, a qual está fundamentada no uso da metodologia Iniciativa Startup Experience, desenvolvida pelo projeto de extensão "Ciência para Todos" da UFPR, no qual os autores deste artigo atuam. Em suma, o trabalho proposto pela Startup "Check" baseia-se em um sistema de controle de digital para gestão de acesso aos espaços físicos da UFPR, incluindo principalmente laboratórios de pesquisa, a partir de ferramentas gratuitas. Assim, é possível monitorar os fluxos de entradas, saídas e possíveis casos de contaminação pelo COVID-19 ou usuários que apresentem sintomas. Através desse sistema - pensado, inicialmente, de maneira mais simples e exequível na UFPR - a solução evoluiu ao longo do tempo, de forma a poder ser escalada/utilizada em vários outros setores.

Considerando a necessidade latente de minimizar os efeitos da pandemia sobre os sistemas socioeconômicos, o objetivo do presente artigo é relatar a experiência dos autores na condução do projeto "Check - Acesso Fácil". O trabalho enfatiza uma metodologia integrativa, questões sobre as soluções desenvolvidas e seu mecanismo de impacto social.

\section{METODOLOGIA}

O projeto "Check - Acesso Fácil" foi desenvolvido em setembro de 2020 pela equipe do projeto de extensão "Ciência Para Todos", do Departamento de Engenharia Elétrica da UFPR, utilizando a metodologia Iniciativa Startup Experience, que consiste em um conjunto de diretrizes utilizadas para a ideação/criação de Startups de base tecnológica. Tal projeto destina-se a divulgação da Ciência, Tecnologia e Inovação para a sociedade. A iniciativa também está vinculada ao Edital "COVID-19 e agora?" da UFPR, que conta com uma equipe multidisciplinar de profissionais, que visam compartilhar informações sobre a doença, conscientizar a população acerca dos métodos de prevenção e, consequentemente, contribuir para o controle da pandemia.

A concepção, prototipagem e testagem do sistema foram realizadas no Núcleo de Pesquisa e Desenvolvimento de Energia Autossustentável (NPDEAS), o qual desenvolve pesquisas relacionadas a diversas áreas do conhecimento (NPDEAS, 2021).

O sistema consiste em disponibilizar $Q R$ Codes, um código de barras bidimensional, que pode ser facilmente escaneado usando a maioria dos smartphones equipados com câmera, cujo código é convertido para uso em um aplicativo que faça a sua leitura. Nesse caso, os $Q R$ Codes foram impressos e fixados nos pontos de acessos do local e, a partir do seu escaneamento, os usuários preencheram um formulário online, 
fornecendo as seguintes informações: nome, registro de entrada/saída e se apresentam ou não com algum sintoma relacionado ao COVID-19. Todas as informações geradas são instantaneamente automatizadas e compiladas em planilhas em uma plataforma, a qual facilita o acesso do gestor à base de dados.

A Figura 1 ilustra a visão geral do formulário gerado com o sistema proposto. Além disso, um vídeo detalhando o sistema e com instruções de criação de ferramentas de registro de acesso digital gratuito encontra-se disponível online (<https://youtu.be/pfbUuLtRJE4>), podendo ser utilizado como suporte informativo.

Figura 1 - Modelo de formulário para substituição do livro-ponto. Cada espaço a ser controlado possui um $Q R C O D E$ no local de entrada/saída. Ao acessar o código com o celular, o usuário é direcionado para uma planilha de registro de acesso conforme o modelo apresentado.

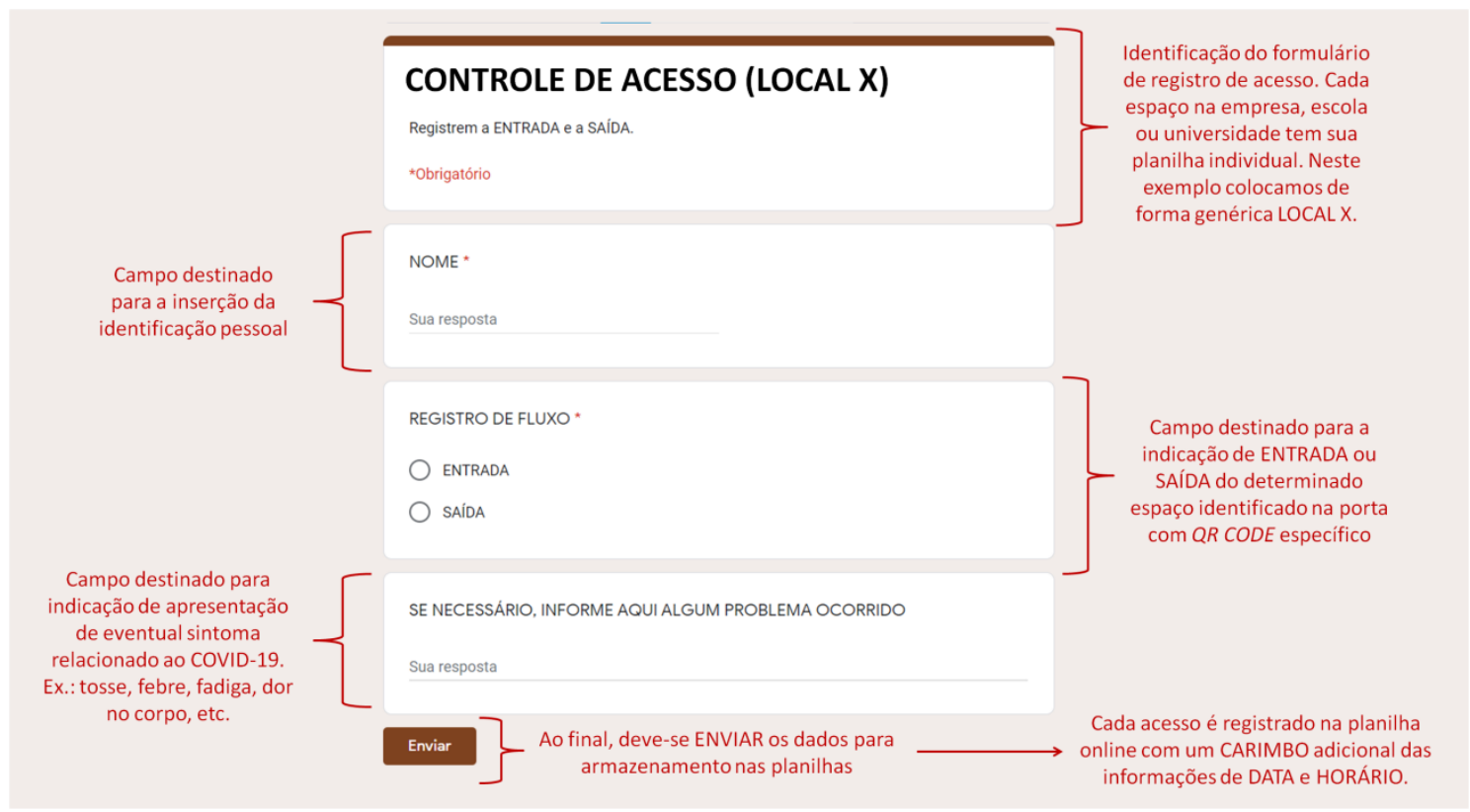

Fonte: Autoria própria (2021).

\subsection{Evolução da solução}

A fim de aprimorar o projeto "Check - Acesso Fácil", foram desenvolvidas estratégias para viabilizar a evolução do sistema, incluindo (i) a concepção de uma Startup; (ii) um protoprojeto da solução semi-automatizada; e (iii) um aplicativo, com a solução automatizada, as quais serão detalhadas a seguir.

\subsubsection{Startup}


A Startup "Check - Acesso Fácil", enquanto empresa recém-criada e em fase de desenvolvimento com forte base tecnológica, foi projetada para atender a demanda da universidade, cujo sistema consiste em produzir conteúdos digitais para exibir a iniciativa nas redes sociais, além de divulgar o trabalho em eventos. O conteúdo pode ser visualizado no link <https://www.ufpr.br/portalufpr/noticias/projeto-da-ufpr-criasistema-de-monitoramento-de-acesso-aos-laboratorios-para-minimizar-riscos-decontaminacao-por-covid-19/>. Essa solução está baseada no desenvolvimento ou melhoramento de um modelo de negócio, preferencialmente escalável, disruptivo e reprodutível.

\subsubsection{Protoprojeto de solução semi-automatizada}

Nessa etapa, foi criada uma função adicional nas planilhas utilizando o VBA (Visual Basic for Applications). Inicialmente uma planilha foi preenchida com os dados de identificação dos usuários, tais como o nome completo, o código de identificação do aluno ou e-mail, através de um framework de busca. Esse sistema permitiu identificar os horários de entrada e saída em que o usuário, com possíveis sintomas ou contaminado, esteve no local, e isso possibilitou a identificação dos potencias colaboradores que estiveram em contato no período de sete dias.

\subsubsection{Automatização do aplicativo}

O aplicativo foi automatizado através do desenvolvimento de uma tabela em Power BI, ou seja, uma plataforma que permite a visualização dos dados de uma planilha em forma de banco de dados de maneira simples e completa. $\mathrm{O}$ aplicativo foi desenvolvido em Dart, uma linguagem de programação criada pela empresa Google em 2011, para a elaboração de aplicativos nativos para iOS ou Android (<https://dart.dev/>). Além disso, contém o kit de desenvolvimento de interface de usuário chamado Flutter, o qual também foi desenvolvido pela Google em 2017. Para isso, foram utilizadas as bibliotecas $Q R$ Flutter, para gerar o $Q R$ Codes, e o Bar Code Scan, para possibilitar a leitura direta do $Q R$ Code. A escolha do framework ocorreu pela grande modularidade, o que permite que qualquer escolha tomada pudesse ser alcançada por ele.

A tabela em Power BI, o BakEnd, utilizada nesse trabalho, é um programa que faz o tratamento de dados, que advém do aplicativo. Além desse tratamento, foi desenvolvido em Node.js, uma plataforma de JavaScript, enquanto que o banco de dados foi realizado em um sistema de gerenciamento denominado de PostgreSQL. 
Ambas as plataformas são livres e gratuitas para o desenvolvimento e comercialização, além de serem amplamente utilizadas e conterem substancial conteúdo relacionado.

Adicionalmente, surgiu a necessidade de um BackEnd, pois o tratamento dos dados deveria ser realizado pela plataforma de Business Inteligência (Inteligência Comercial) antes do envio para o banco de dados, a fim de garantir a não ocorrência de erros durante a aplicação. A criação desse banco de dados promoveu a comunicação entre o aplicativo e a tabela de $B I$, bem como o tratamento de dados mencionado pelo BackEnd, o que garante a aplicação correta do sistema.

\section{RESULTADOS E DISCUSSÃO}

\subsection{Solução inicial}

A Figura 2 representa simbolicamente um modelo de planilha com o conjunto de dados gerados a partir da leitura do $Q R$ Code. A título de exemplificação, os nomes, atribuídos aleatoriamente, servem para fins de privacidade e sigilo em relação aos dados reais obtidos.

Como pode ser observado na marcação em vermelho, o nome "Ana" refere-se ao indivíduo que apresenta algum tipo de sintoma frequentemente relacionado ao COVID19. Assim, o indivíduo de nome "Maria", que estava presente no local, no mesmo dia e horário, deverá ser isolado, da mesma forma que "Ana", seguindo as recomendações e protocolos institucionais para casos de suspeita ou confirmação do vírus. Dessa forma, é possível obter informações que atendam aos requisitos de prevenção e redução da disseminação da doença. 
Figura 2 - Planilha de dados online com o registro dos acessos cadastrados a partir do formulário.

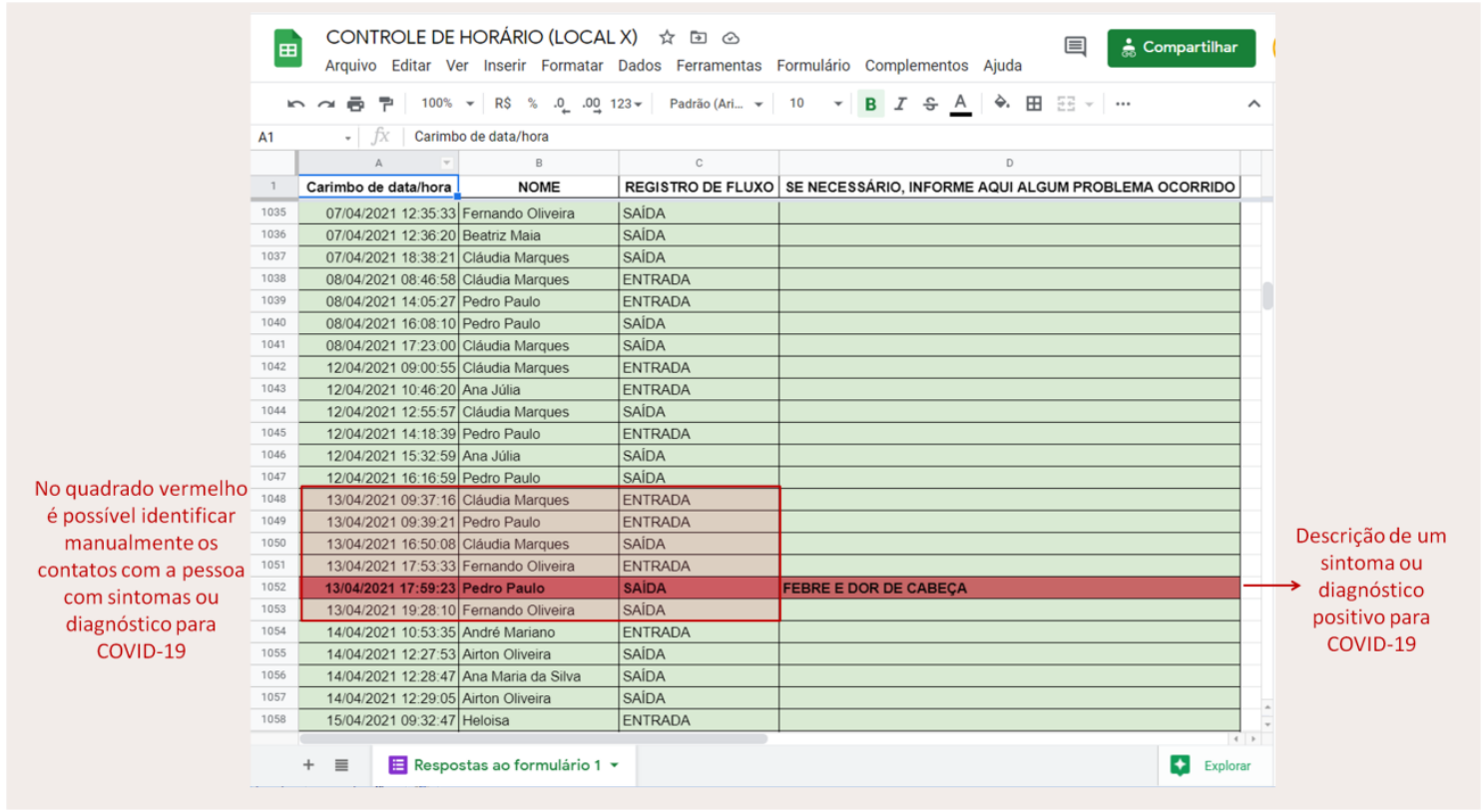

Fonte: Autoria própria (2021).

\subsection{Solução semi-automatizada}

A solução inicial serviu como base para a concepção de um produto mínimo viável ou Minimum Viable Product (MVP), e semi-automatizado pelo VBA, na qual as planilhas apresentaram a correlação dos dados dos indivíduos contaminados e de indivíduos que presentes no mesmo local do contaminante, conforme pode ser visualizado na Figura 3. 
Figura 3 - Interface da planilha do VBA. A: Visão geral; B: Correlação de indivíduos em contato com o contaminante.

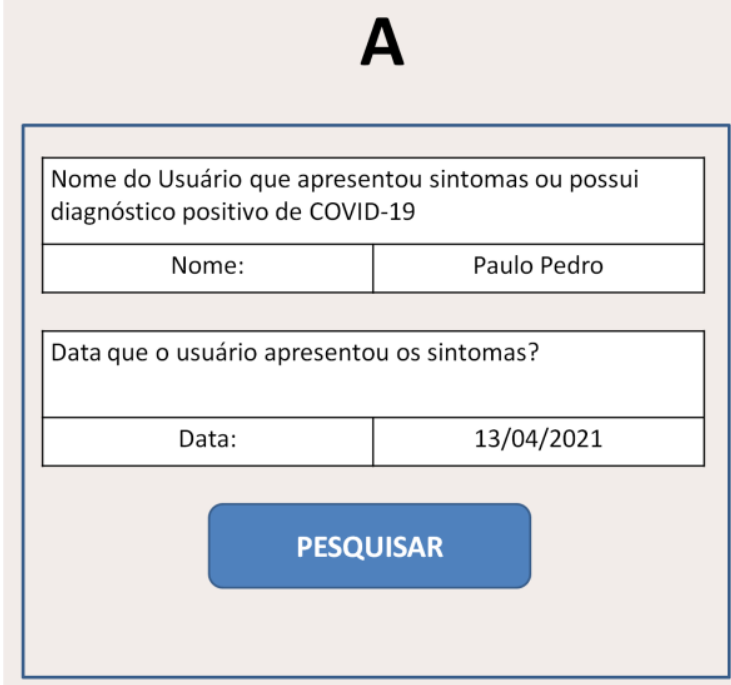

B

Pessoas que entraram em contato com o USUÁRIO nos últimos 7 dias:

Nome dos contatos:

\begin{tabular}{|c|r|l|}
\hline \multicolumn{2}{|c|}{ Nome dos contatos: } \\
\hline Ana Júlia & EMAIL & TELEFONE \\
Beatriz Maia & EMAIL & TELEFONE \\
Cláudia Marques & EMAIL & TELEFONE \\
Fernando Oliveira & EMAIL & TELEFONE \\
\hline
\end{tabular}

Fonte: Autoria própria (2021).

De acordo com a Figura 3A, a interface demonstra o momento em que foi identificado o indivíduo com sintomas de COVID-19. Em contrapartida, a Figura 3B ilustra a relação obtida automaticamente dos indivíduos que entraram em contato com o contaminante nos últimos 7 dias.

\subsection{Solução automatizada (aplicativo)}

O aprimoramento do protoprojeto resultou no desenvolvimento da solução totalmente automatizada. A interface inicial do aplicativo foi destinada para que o usuário possa se conectar ao sistema proposto, registrando-se (Figura 4) ou inserindo seus dados previamente cadastrados (Figura 5). 
Figura 4 - Interface de registro do aplicativo.

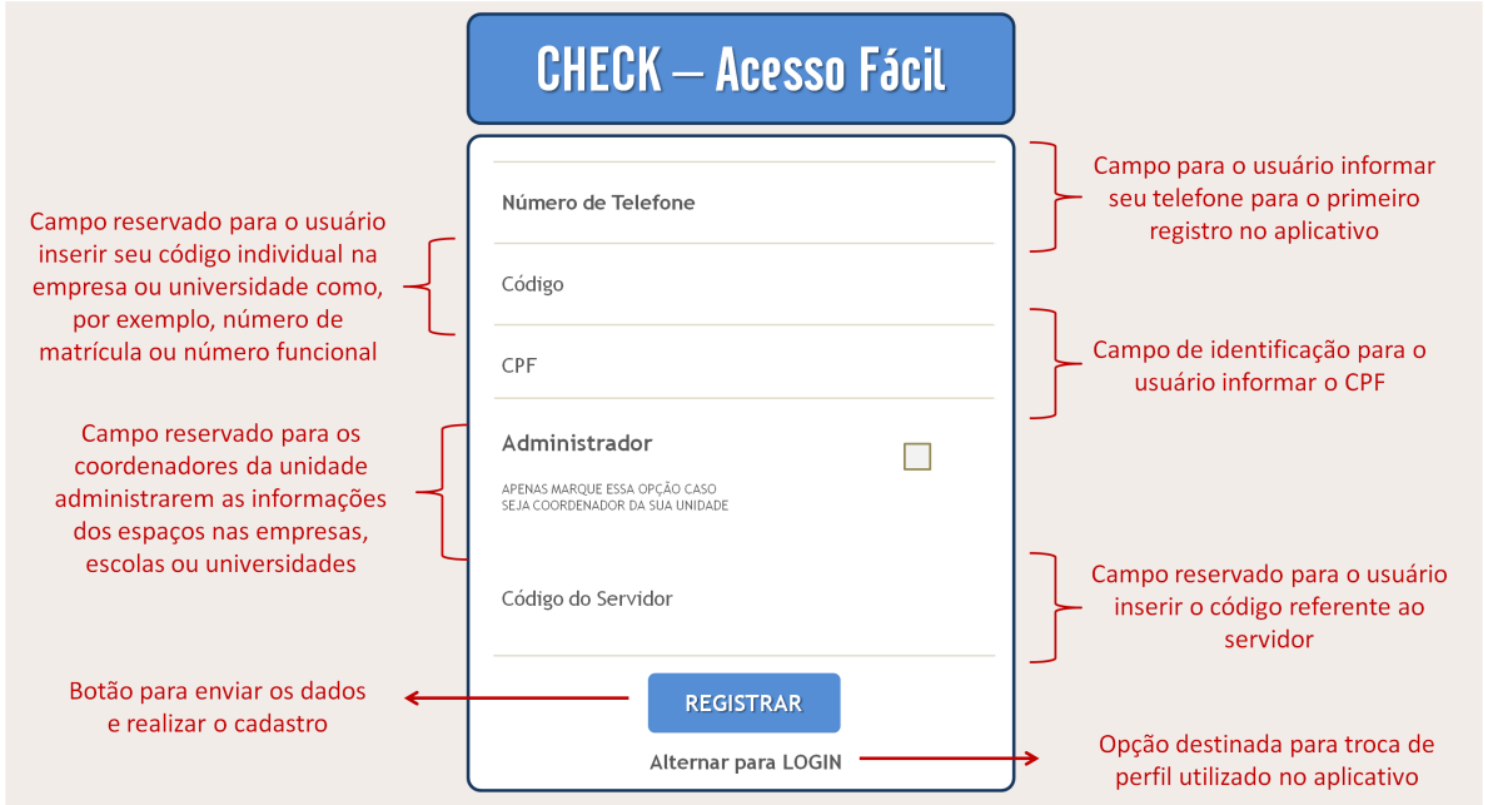

Fonte: Autoria própria (2021).

Figura 5 - Interface de entrada no aplicativo.

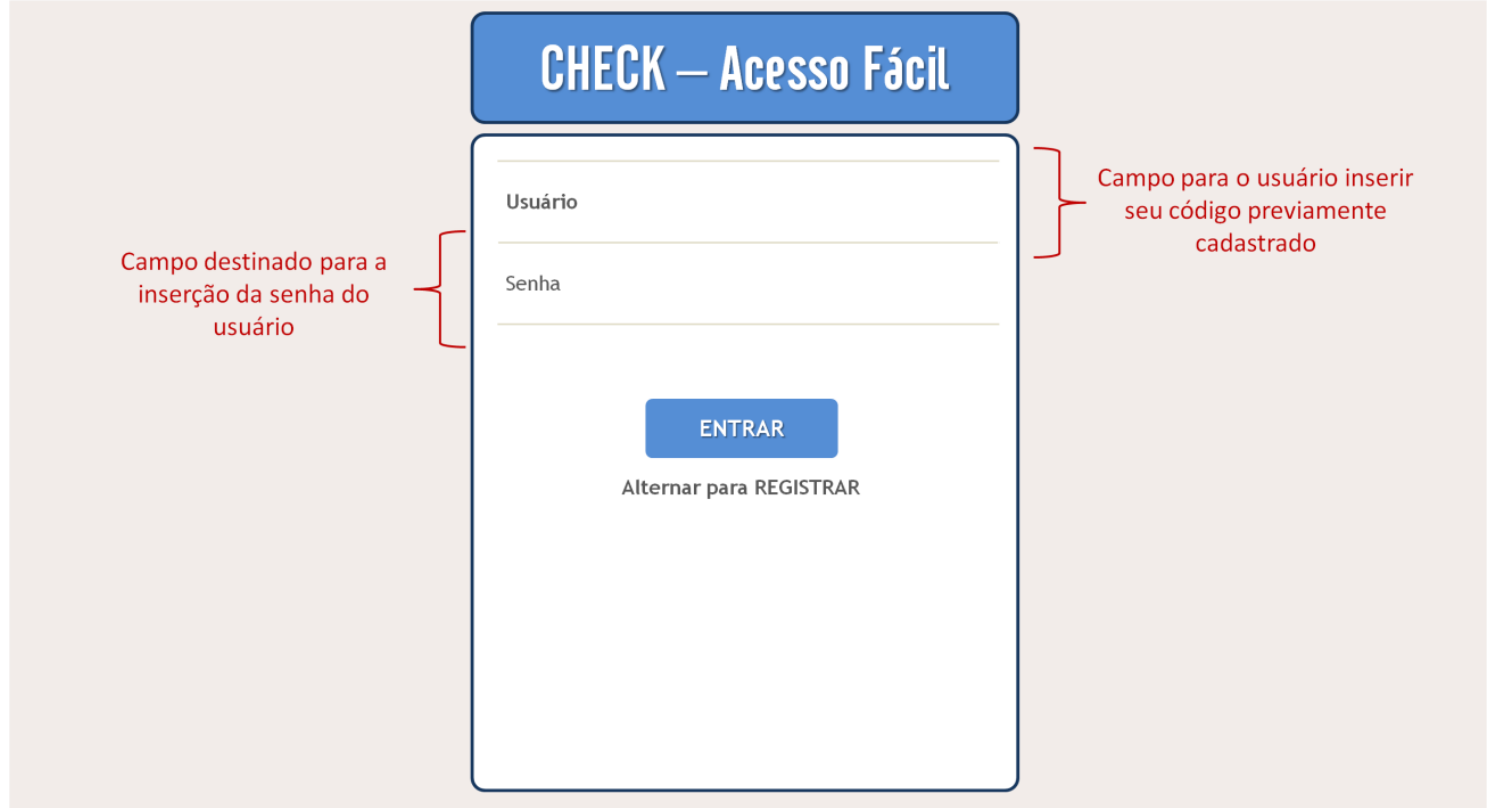

Fonte: Autoria própria (2021).

Após a entrada no aplicativo, usuário tem acesso a 5 seções de interatividade da solução, incluindo: 1 - QR Code; 2 - Dicas; 3 - Opções; 4 - Estou com COVID; e 5 Logout, conforme apresentado na Figura 6. 
Figura 6 - Interface de interatividade do aplicativo.

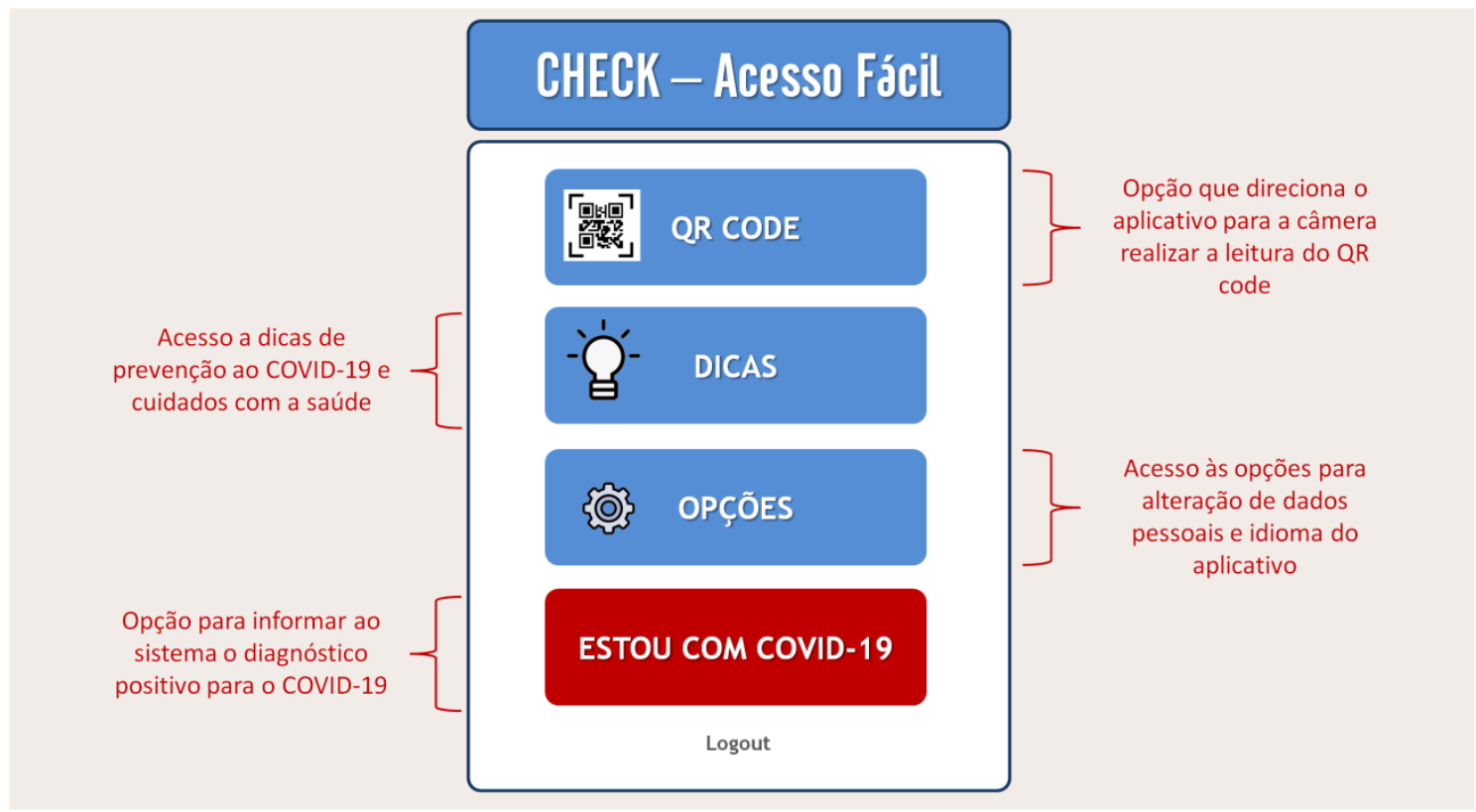

Fonte: Autoria própria (2021).

As ações da solução são divididas entre alunos/visitantes e administradores. Uma vez selecionada a opção $Q R$ code, os usuários que pertencem ao grupo de alunos/visitantes, são direcionados para o escaneamento do código. Os usuários da área administrativa são redirecionados para uma interface diferente, a "Tela do Admin", que possibilita a utilização do $Q R$ code, da mesma forma que o grupo anterior. Além disso, é possível a criação e edição de salas para gerar novos códigos (Figura 7). Ao selecionar a opção "Criar Sala", o administrador insere o nome da sala, seu código e adiciona a metragem do local (Figura 8). Posteriormente, é gerado um $Q R$ code, o qual pode ser impresso e estabelecido no local desejado. 
Figura 7 - Interface da Tela do Administrador da sala.

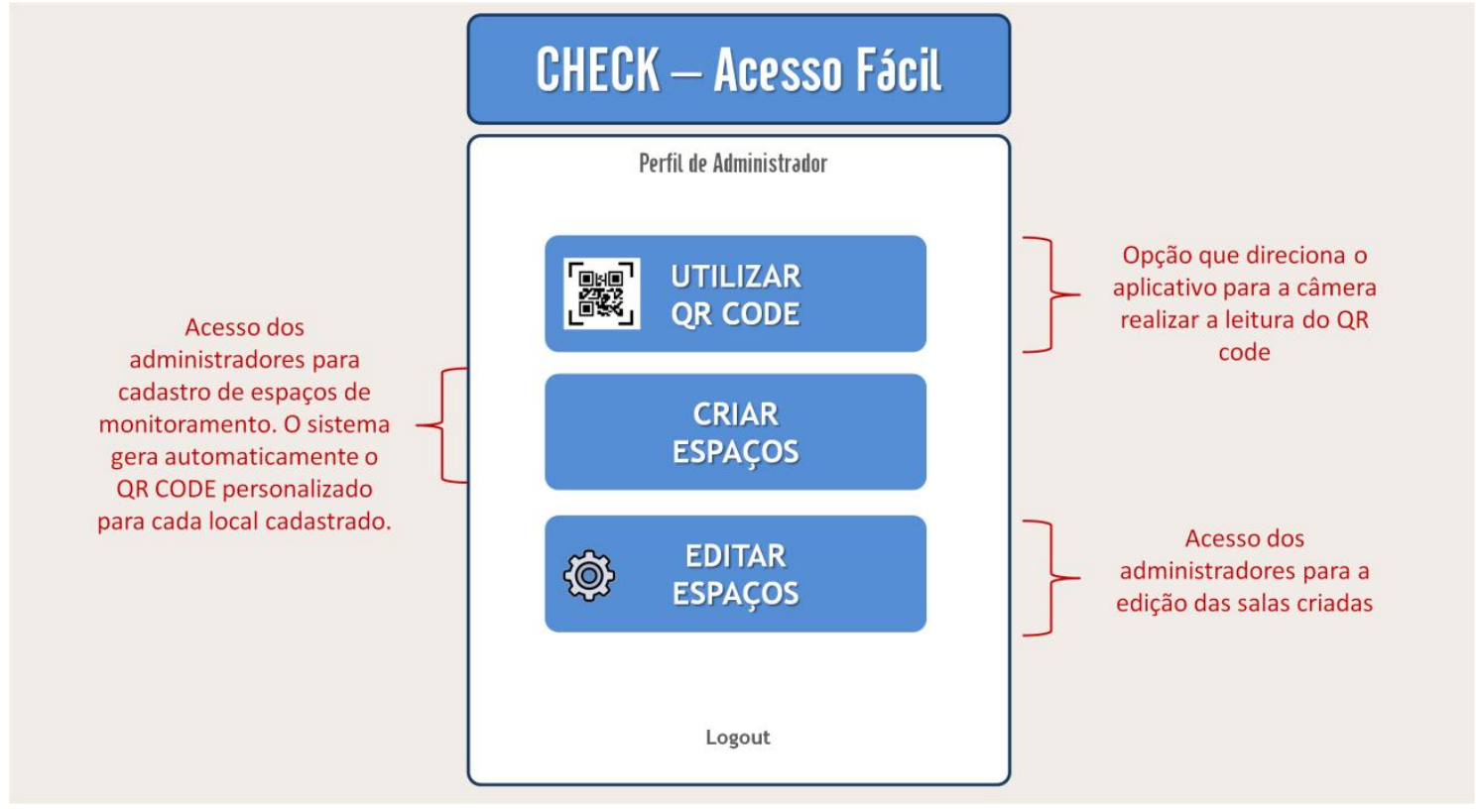

Fonte: Autoria própria (2021).

Figura 8 - Interface da tela de criação da sala.

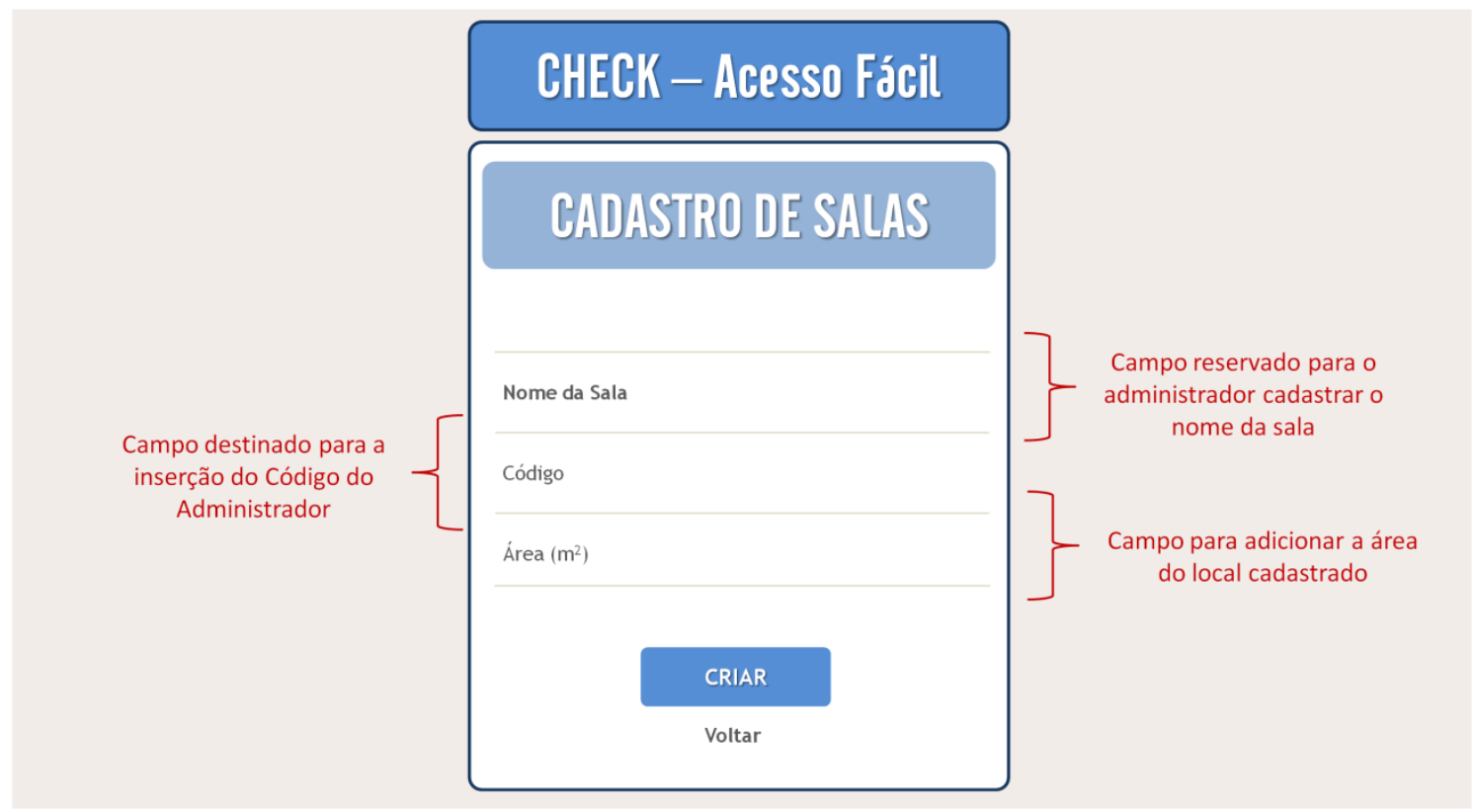

Fonte: Autoria própria (2021).

A seção "Dicas" (Figura 9) é destinada para informações e lembretes sobre prevenção do COVID-19, através de imagens e textos informativos. Além disso, em um intervalo de 30 min a 1 hora, o Pop-up, um tipo de janela que se abre no navegador ao 
acessar uma informação adicional específica ao usuário, é acionado para notificar sobre uma dica/lembrete novo.

Figura 9 - Interface da Tela de dicas.

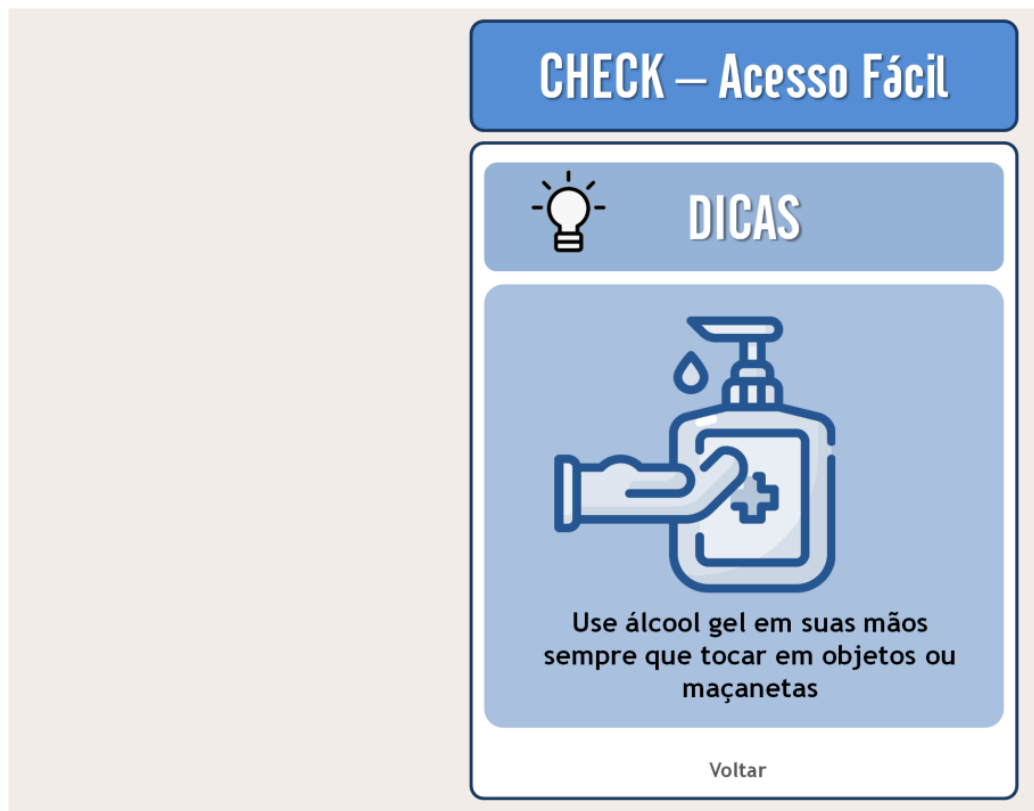

Fonte: Autoria própria (2021).

Em relação a seção “Opções” (Figura 10), é possível alterar os dados do usuário e realizar a alteração da linguagem do aplicativo. Finalmente, ao selecionar a seção "Estou com Covid", o aplicativo direciona para uma nova interface, onde o usuário tem acesso aos procedimentos a serem realizados no tratamento da doença, 
Figura 10 - Interface da Tela de opções.

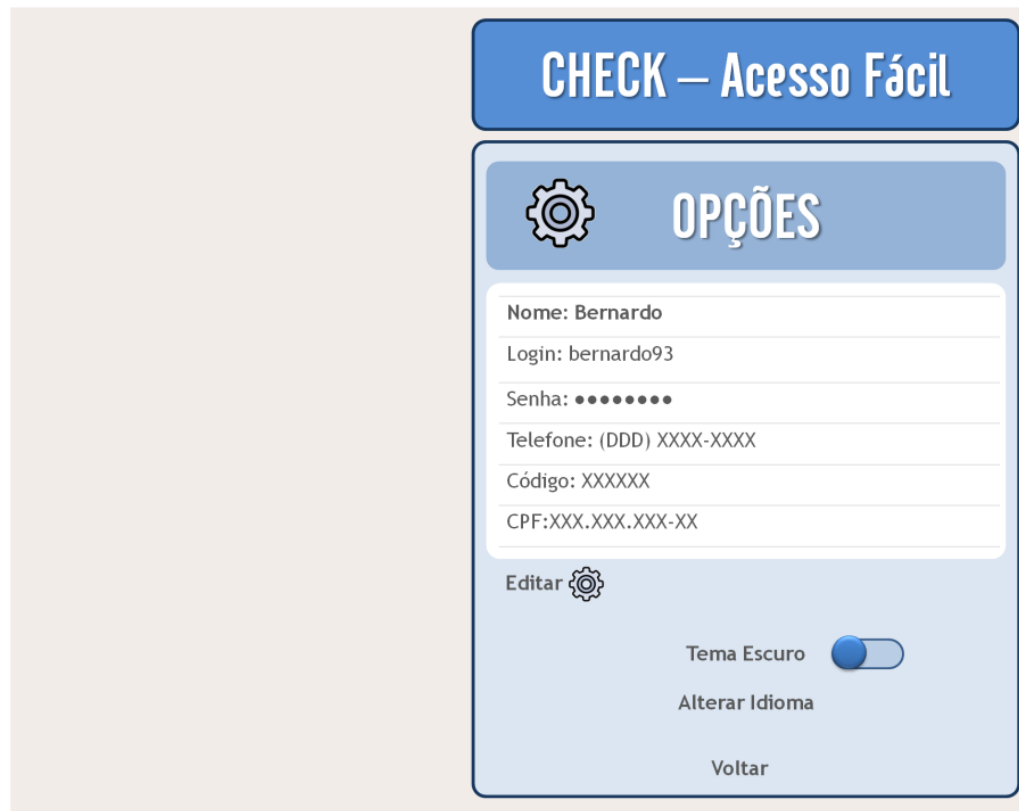

Fonte: Autoria própria (2021).

\subsection{Avaliação das soluções}

A Figura 11 ilustra um diagrama esquemático com os resultados observados durante o estudo das três soluções.

Figura 11 - Diagrama comparativo com as soluções propostas.

\begin{tabular}{|c|c|c|c|}
\hline & $\begin{array}{l}\text { MONITORAMENTO } \\
\text { MANUAL }\end{array}$ & $\begin{array}{l}\text { MONITORAMENTO } \\
\text { SEMIAUTOMATIZADO }\end{array}$ & $\begin{array}{l}\text { MONITORAMENTO } \\
\text { AUTOMATIZADO }\end{array}$ \\
\hline VANTAGENS & $\begin{array}{l}\text { - Sistema adequado para } \\
\text { pequenos grupos. } \\
\\
\text { - Tutorial de implantação } \\
\text { disponibilizado } \\
\text { gratuitamente pelo } \\
\text { projeto. }\end{array}$ & $\begin{array}{l}\text { Monitoramento das } \\
\text { planilhas é realizada por } \\
\text { VBA e permite a busca por } \\
\text { contados dos contaminados } \\
\text { de forma semi- } \\
\text { automaizada e rápida. }\end{array}$ & $\begin{array}{l}\text { Ideal para grandes } \\
\text { empresas, escolas e } \\
\text { universidades. } \\
\text { Solução escalável } \\
\text { permitindo a operação na } \\
\text { forma de uma startup } \\
\text { com monetização } \\
\text { recorrente. }\end{array}$ \\
\hline DESVANTAEES & $\begin{array}{l}\text { Planilhas geradas são } \\
\text { simples e a interpretação } \\
\text { dos dados é feita de forma } \\
\text { manual. }\end{array}$ & $\begin{array}{l}\text { Requer treinamento do } \\
\text { administrador das salas } \\
\text { para monitorar os dados. } \\
\text { - Requer um profissional } \\
\text { experiente em VBA para } \\
\text { programar as planilhas. }\end{array}$ & $\begin{array}{l}\text { A continuidade da solução } \\
\text { depende da } \\
\text { sustentabilidade } \\
\text { econômica da startup para } \\
\text { viabilizar o serviço de } \\
\text { qualidade e com } \\
\text { continuidade. }\end{array}$ \\
\hline
\end{tabular}

Fonte: Autoria própria (2021). 
A solução inicial implementada no NPDEAS, apresentou como principal vantagem o fácil desenvolvimento e o custo-benefício, visto que é gratuita, necessitando apenas seguir o tutorial. No entanto, apresenta planilhas simples, sem automatização para realizar o monitoramento dos casos, cujo procedimento precisa ser realizado manualmente. Além disso, essa solução possui como limitação a dependência de um aparelho de celular e de uma rede de internet, seja ela Wi-Fi ou dados móveis, para sua utilização, dificultando o seu funcionamento na ausência desses requisitos.

Diferentemente da inicial, a solução semi-automatizada permite que as planilhas com os dados e possíveis casos sejam analisadas de forma automática. Elencando os dados de 7 dias, é possível verificar a presença ou não de algum indivíduo contaminado e das pessoas que entraram em contato com ele. Contudo, essa automatização realizada eleva o custo do sistema, uma vez que, para a replicação dessas funcionalidades, depende-se de um profissional capacitado com conhecimento técnico para programar todas as planilhas necessárias, ou seja, uma planilha para cada espaço monitorado.

A solução totalmente automatizada, em forma de aplicativo como o desenvolvido pelo projeto, pode ser implementada em todo o tipo de estabelecimento, seja ele com grupos pequenos ou grandes, já que nesta fase todos os dados serão lidos pelo próprio sistema, sem a necessidade de uma análise individual de cada planilha. Porém, da mesma maneira que a semi-automatizada, essa solução apresenta um elevado custo, pois exige profissionais de conhecimento técnico em programação para o desenvolvimento de uma solução equivalente.

Essa última solução poderá ser desenvolvida como forma de produto de uma Startup, visto que é um sistema totalmente automatizado, facilitando, portanto, a sua escalabilidade. A possibilidade de monetização se dá por meio da venda e implementação do sistema nas diferentes empresas, a fim de monitorar os dados dos funcionários e prestar suporte às contratantes e, desta forma, obter a sustentabilidade econômica para manutenção das atividades.

\subsection{Divulgação do sistema para a sociedade}

A fim de difundir os resultados do sistema desenvolvido e relatado neste trabalho, as redes sociais da internet "Instagram" e "LinkedIn" foram utilizadas como veículo de comunicação com a sociedade. As primeiras ações, baseadas na publicação de conteúdo, objetivaram a apresentação detalhada do projeto "Check - Acesso Fácil", divulgando a sua missão e valores. Mais tarde, o projeto "Ciência para Todos" da UFPR, foi 
apresentado nos mesmos moldes. Paralelamente, como o sistema refere-se a um método de controle e prevenção do COVID-19, uma seção explicativa sobre a pandemia foi criada nestas redes socais, a fim de abordar seu impacto no âmbito social e universitário.

Com a ampla divulgação, o projeto "Check - Acesso Fácil" participou do Pitch Paraná, um evento subsidiado pelo Governo do Estado por meio da Tecnologia da Informação e Comunicação do Paraná (Celepar) e da Superintendência Geral de Inovação da Casa Civil, que tem como propósito alavancar o ecossistema de inovação no Estado do Paraná (GOVERNO DO PARANÁ, 2021). Essa iniciativa foi o ponto de conexão entre as Startups, especialistas e investidores de diversos setores interessados na área de inovação e em busca de conhecimento.

Seguindo uma estratégia de divulgação bem estabelecida, foram criadas publicações que convocavam o público a divulgar a participação no Pitch Paraná. As iniciativas foram divididas em duas fases, sendo que a primeira consistiu em apresentar o projeto "Check - Acesso Fácil", conforme pode ser visualizado no link <https://youtu.be/3O7uNNSSX2U> que, mais tarde, foi selecionado entre as 25 Startups de maior impacto inovador. Na segunda fase, o projeto contemplou a apresentação de um novo Pitch, de acordo com o link <https://youtu.be/JiNyW2G9J7c>. Nessa última etapa do processo, a apresentação do projeto foi divulgada ao vivo, através do canal da Superintendência Geral de Inovação (<https://youtu.be/XAXSNyiNPI0>), em 4 de novembro de 2020. A partir da avaliação destes conteúdos, observou-se, entretanto, a necessidade de aprimorar o modelo de negócios, uma vez que o foco do projeto estava voltado apenas para o escopo da pandemia, com o propósito de amenizar os riscos de contágio pelo Coronavírus por profissionais da UFPR.

Na mesma linha de ação, o projeto "Check - Acesso Fácil" também participou do evento Arena Inovação (<https://insta.ufpr.br/portal/inovacao/arena-inovacao/>), desenvolvido pela UFPR.

Assim, fez-se necessário o estudo de melhorias adicionais para validar e viabilizar o produto, o qual baseia-se em um MVP. Essas ações incluem a possibilidade de maior abrangência em termos de aplicabilidade, a demanda de agregar valor ao produto, a definição do público-alvo e o escalonamento. Independente destes aspectos, a equipe envolvida identificou ideias e potenciais soluções tecnológicas inovadoras que podem

\footnotetext{
${ }^{1}$ Pitch é uma apresentação rápida e direta de um projeto ou produto com o propósito de 'vender' a ideia a um sócio, investidor, parceiro ou cliente.
} 
trazer benefícios ao cidadão, além da integração à política de Estado, e aprimorou a sua comunicação e visão empresarial.

Adicionalmente, o sistema proposto também foi divulgado para a sociedade através de entrevistas concedidas para emissoras de televisão e rádio, como pode ser visualizado nos links de acesso <https://globoplay.globo.com/v/9020477/programa/> e $<$ https://bandnewsfmcuritiba.com/ufpr-lanca-tutorial-para-criar-sistema-que-monitorasaude-de-funcionarios/>. Esse mecanismo resultou em uma maior visibilidade para o projeto somado à experiência da equipe. Além disso, o uso da mídia como ferramenta de divulgação facilita o acesso a informações essenciais para a sociedade, de forma segura, considerando a continuidade das atividades desenvolvidas durante o período de pandemia.

\subsection{Projeto piloto}

O desenvolvimento do sistema de controle de acesso, associado à sua divulgação para a sociedade, abriu caminho para a rápida evolução do projeto através do desenvolvimento de um projeto piloto a ser implementado nas instalações do Hospital Veterinário (HV) da UFPR. A ideia é realizar o mapeamento de todas as áreas do local, através de planilhas de monitoramento (Figura 12).

Através dessa abordagem, é possível verificar a logística do ambiente e gerar um código específico para cada dependência, a qual apresenta um código que facilita a aplicação do Power BI. Com a futura aplicação do sistema no HV, o projeto será validado e escalonado para implementação em outras potencias instituições. 
Figura 12 - Visualização de um exemplo de planilha com as siglas desenvolvidas para cada sala do Hospital Veterinário.

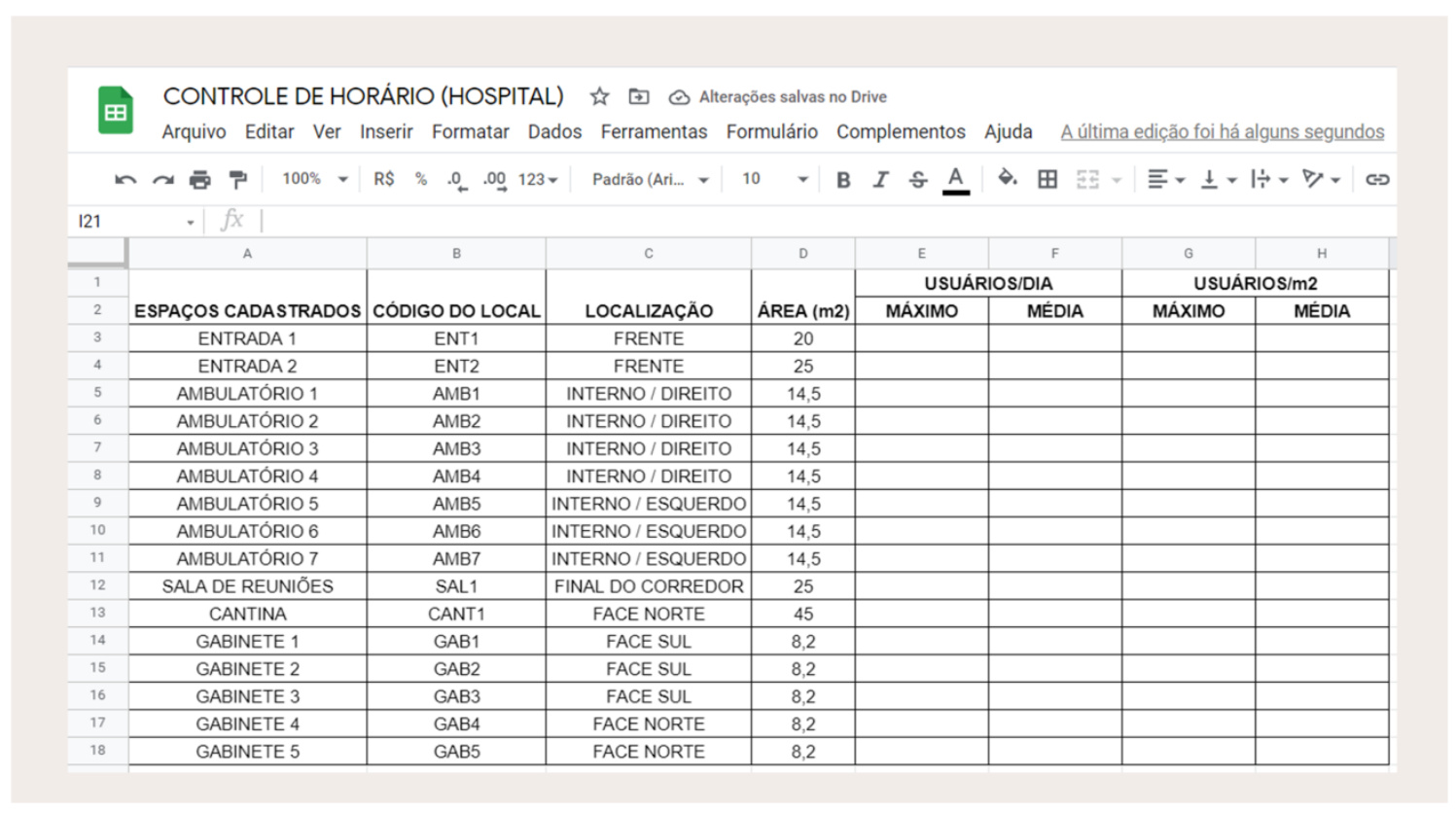

Fonte: Autoria própria (2021).

\section{CONCLUSÃO}

O desenvolvimento deste relato de experiência permitiu constatar a possibilidade de utilizar o sistema "Check - Acesso Fácil" como uma ferramenta simples, barata e eficiente que ajuda a controlar a disseminação do COVID-19, e com isso proporcionar maior qualidade de vida, proteção e segurança à sociedade.

Portanto, através deste trabalho interdisciplinar desenvolvido a partir da metodologia Iniciativa Startup Experience no projeto de extensão Ciência para Todos, foi desenvolvida uma solução que permite, através do monitoramento de acessos, o controle da saúde de equipes de trabalho em empresas e, até mesmo, alunos e professores em universidades e escolas. Todo o trabalho envolveu a participação de alunos de graduação e professores da UFPR, com o desenvolvimento nos discentes de competências de gestão de projeto, soft skills, inovação, empreendedorismo, interdisciplinaridade e extensão tecnológica inovadora.

\section{AGRADECIMENTOS}

Os autores agradecem ao Edital 'Covid-19 e agora?' do Setor de Tecnologia (UFPR), pelo fomento à esta iniciativa, a qual permitiu que mais graduandos pudessem atuar no desenvolvimento de uma solução em prol da UFPR; ao Hospital Veterinário da 
UFPR, por permitir a avaliação do protótipo em suas dependências; à equipe da Arena Inovação e Instituto de Soluções Tecnológicas Aplicadas (INSTA); ao Governo do Estado do Paraná; e ao projeto "Ciência para Todos" e toda sua equipe, que apoiaram a iniciativa. Os autores também agradecem os professores da UFPR: Álvaro Luis Mathias, Vanessa Merlo Kava, Michele Rigon Spier, Márcio Fontana Catapam e aos alunos da Empresa Júnior (Polimerase Jr.) do Curso de Farmácia pela utilização do sistema piloto em suas dependências para validação da tecnologia.

\section{REFERÊNCIAS}

BHATTACHARYA, S.; MADDIKUNTA, P. K. R.; PHAM, Q.-V.; GADEKALLU, T. R.; KRISHNAN, S. R.; CHOWDHARY, C. L.; ALAZAB, M.; PIRAN, M. J. Sustainable Cities and Society, v. 65, n. 102589, 2021.

GOVERNO DO PARANÁ. Paraná - Governo do Estado, Superintendência Geral de Inovação. Pitch Paraná. Disponível em: < http://pitchparana.pr.gov.br/\#>. Data de acesso: 13 de abril de 2021 .

HOSSAIN, M. The effect of the Covid-19 on sharing economy activities. Journal of Cleaner Production, v. 280, n. 124782, 2021.

KUMMITHA, R. K. R. Smart technologies for fighting pandemics: The technoand human- driven approaches in controlling the virus transmission. Government Information Quarterly, v. 37, n. 101481, 2020.

MOUTER, N.; COLlEWET, M.; DE WIT, G. A.; ROTTEVEEL, A.; LAMBOOIJ, M. S.; KESSELS, R. Societal Effects Are a Major Factor for the Uptake of the Coronavirus Disease 2019 (COVID-19) Digital Contact Tracing App in The Netherlands. Value in Health, In Press, 2021.

\section{NPDEAS. Núcleo de Pesquisa e Desenvolvimento de Energia} Autossustentável (NPDEAS). Disponível em: <http://npdeas.blogspot.com/>. Data de acesso: 14 de abril de 2021 .

SANTANA, H. S.; DE SOUZA, M. R. P.; LOPES, M. G. M.; SOUZA, J.; SILVA, R. R. O.; PALMA, M. S. A. et al. How chemical engineers can contribute to fight the COVID-19. Journal of the Taiwan Institute of Chemical Engineers, v. 116, p. 67-80, 2020. 
SILVA, M. R. F. et al. Reflexões sobre as ações extensionistas e de pesquisa no combate à COVID-19 na Universidade do Estado do Rio Grande do Norte. Brazilian Journal of Health Review, Curitiba, v. 3, n. 2, p.3622-3646 mar./abr. 2020.

UNESCO. COVID-19 impact on education. Montreal: UNESCO Institute for Statistics, 2020.

Recebido em: 16 de Abril de 2021.

Aceito em: 05 de Maio de 2021. 